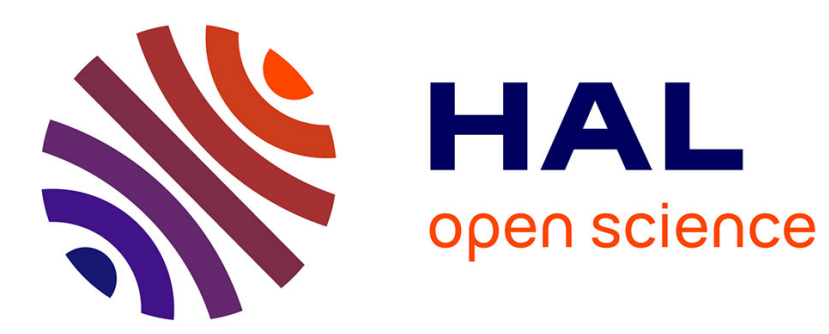

\title{
Ambient Intelligence: From Scenario Analysis towards a Bottom-Up Design
}

\author{
Andrei Olaru, Amal El Fallah-Seghrouchni, Adina Magda Florea
}

\section{To cite this version:}

Andrei Olaru, Amal El Fallah-Seghrouchni, Adina Magda Florea. Ambient Intelligence: From Scenario Analysis towards a Bottom-Up Design. IDC 2010 - 4th International Symposium on Intelligent Distributed Computing, Sep 2010, Tangier, Morocco. pp.165-170, 10.1007/978-3-642-15211-5_17 . hal-00661848

\section{HAL Id: hal-00661848 \\ https://hal.science/hal-00661848}

Submitted on 20 Jan 2012

HAL is a multi-disciplinary open access archive for the deposit and dissemination of scientific research documents, whether they are published or not. The documents may come from teaching and research institutions in France or abroad, or from public or private research centers.
L'archive ouverte pluridisciplinaire HAL, est destinée au dépôt et à la diffusion de documents scientifiques de niveau recherche, publiés ou non, émanant des établissements d'enseignement et de recherche français ou étrangers, des laboratoires publics ou privés. 


\title{
Ambient Intelligence: From Scenario Analysis Towards a Bottom-Up Design*
}

\author{
Andrei Olaru, Amal El Fallah Seghrouchni, and Adina Magda Florea
}

\begin{abstract}
In the domain of Ambient Intelligence, research goals are many times driven by scenarios that help envisage a world enriched by ambient, pervasive, intelligent services. So far, scenarios have most times presented the perception that one person has upon the system, with few details on how the system should work in the background in order to deal with realistic requirements. In this paper, starting from scenarios presented in previous research, we identify features and requirements for AmI systems and propose two new scenarios, focusing on the way information is exchanged beyond the perspective of, and transparent to, the user of the system. We also agentify one of the scenarios, giving insight on how an AmI system may be built, using software agents, in order to fulfill the requirements.
\end{abstract}

\section{Introduction}

Probably the two best known and most influential papers on related to Ambient Intelligence scenarios and to AmI as a vision came from Weiser in 1995 [9] and from the IST Advisory Group, in 2001 [3]. They describe Ubiquitous Computing and Ambient Intelligence ("AmI", for short): an electronic environment that is present in all things that surround us, as clothes, furniture, objects in our home, vehicles and

\footnotetext{
* Original publication at

http://www.springerlink.com/content/9328537t12571460/

Andrei Olaru

University Politehnica of Bucharest, Splaiul Independentei 313, 060042 Bucharest, Romania

Amal El Fallah Seghrouchni

LIP6, University Pierre et Marie Curie, 104 Avenue du President Kennedy, 75016 Paris, France

Adina Magda Florea

University Politehnica of Bucharest, Splaiul Independentei 313, 060042 Bucharest, Romania

e-mail: cs@andreiolaru.ro·amal.elfallah@lip6.fr·adina@cs.pub.ro
} 
buildings. All things around us (both future "smart" objects and already existing electronic devices) will be connected, web-present [5] and interoperable, will offer intelligent user interfaces and together they will collaborate towards the assistance of people in their daily lives, but also in situations of emergency.

The visions of Weiser and the ISTAG group, together with others [2], describe AmI and its features and challenges with the help of various scenarios. The features of AmI fall into two quite clear categories: intelligent user interfaces (IUI) and an intelligent manner of managing information throughout the system. While most scenarios are centered around the individuals and therefore emphasize the advanced interfaces (like speech recognition, for instance)which is important for the naturalness and invisibility of AmI, we believe that the issue of information management is at least equally important and brings more challenges, not necessarily related to the technologies implied, but mostly related to the internal design and architecture.

In this paper, we briefly analyze scenarios from previous research (Section 2) and identify common features of envisaged or implemented Ambient Intelligence systems, focusing on the layer of AmI concerned with the management of information - above the hardware and network, and below the user interface. We present two new scenarios that emphasize these features, as well as the need for a scaling, dependable and reliable system (Section 3). Finally, we introduce an agentification of one of the scenarios, giving insight on how a distributed, software agent-based AmI system may be built (Section 4).

\section{Scenarios for Ambient Intelligence}

Weiser's scenario featuring Sal [9] is one of the first scenarios for Ambient Intelligence. A first important thing is that when the alarm clock in the scenario - an intelligent appliance - asks "coffee", the only responses that the clock can interpret are "yes" and "no". That is, the appliance can only understand events that are relevant to its function. Sal's house has intelligent windows that can display traces only of those people that are neighbours, and also considering privacy. Sal marks some news (from a printed paper) with a smart pen, having the associated text sent to her office - the pen is able to contact a service associated with the paper and make the text available in the appropriate context, while keeping Sal's information private. Other services are mentioned, relating to the most common points in AmI scenarios: localization and information on points of interest. Towards the end, Sal succeeds in finding a person (named Mary in the scenario) by means of associations between context data related to the time of the meeting, the place, the number of people, and also to the fact that Sal did not previously know Mary.

The scenarios created by the ISTAG group envision AmI of 2010 [3]. The "Maria" scenario emphasizes the movement of the user's electronic identity, credentials, preferences and data with her, seamlessly, as well as the capacity to easily use local resources (vehicles, utilities, computing and communication capabilities). The "Dimitrios" scenario is based on very advanced digital avatars (D-Me) that 
can interact naturally with other persons and take context-aware decisions: the senior person's D-Me contacts Dimitrios because he has the same heart condition, and Dimitrios's D-Me finds a child of the same age and situation with his own, for socializing and educational purposes, thanks to common context. The "Carmen" scenario includes a range of services like car pooling, internet shopping, smart fridges, traffic information, vehicle-to-vehicle communication. Finally, in "Anette and Solomon", AmI features natural communication and advanced semantic processing capabilities. What we find interesting in the ISTAG scenarios, apart from the advanced human-machine interfaces, is that most services already exist in the present day, just that in the scenarios the system is capable to provide information and services just in time, they are easier to access and much more context-awareness is present. However, the presented services seem to be centralized - which may not scale well - and they do not seem to have much in common - aggregating information coming from different services may lead to more and better capabilities.

Other scenarios in the Ambient Intelligence field feature context-aware suggestions and files that move between devices to follow the user [7], seamless transfer of network connections, workspace and video conversation to use local devices [1], web-present objects and context-aware activation of suggestions [5], choice of the manner of notification in function of user's context $[5,8]$.

\section{Two New Scenarios}

In this section we will present two new scenarios, that give an insight on how an Ambient Intelligence system may work internally. Details are focused on the application layer of the system, on how information is managed and how decisions are taken in function of context. Having this focus, we will consider that users are using today's hardware and connectivity, but devices will be enriched with software agents (that we will call AmI agents), that will form the application layer of the system.

Scenario 1. A senior person walks on the street towards her house. In the pocket she has a mobile phone with an AmI software agent installed, featuring Bluetooth and GSM connectivity and in communication with a multipurpose sensor that monitors vital signs. The AmI agent has been configured to communicate the least possible, so normally it doesn't initiate connections. The person lives in a small basement apartment. As she climbs down the stairs, she falls and loses consciousness for a few moments.

In this short time, the vital signs sensor detects that the situation is not life threatening and no major injury occurred, but care may be needed. The personal medical assistant that cares for this user should be called right away. This reasoning is done by a dedicated module of the AmI agent, that is especially designed for senior or disabled people. As there is no GSM signal at this location, the AmI agent searches for another resource that can offer communication services. It activates Bluetooth and finds a device that also runs an AmI agent. It provides to the other agent some 
information about the context: there is someone that needs urgent communication by phone. No personal details are provided. The other agent detects that this context fits its activity history: it has helped with this kind of actions before and it accepts the task without the need for owner's confirmation. The agent of the senior person then gives to the other agent a number and a message to be sent. While the senior becomes conscious again, the AmI agent receives, by means of another Bluetooth phone in the area, the confirmation from the nurse. She will arrive in just a few minutes.

Scenario 2. On the largest stadium of an European capital, a concert is going to be held, by a popular rock group of the time. Hundreds of thousands of people are participating. Most of them have mobile phones or smartphones which run AmI agents. Young people are more permeable to new technologies, and the agents are configured to communicate with other agents that share the same context, while keeping personal data private. All participants share the space, time and activity context. AmI agents form a temporary, anonymous social network, communicating not by means of the Internet or by GSM, but by local connectivity like Bluetooth or WiFi ad-hoc networking. They exchange, anonymously, interesting news or links that are related to the event and to the band. The users made that information public and are not necessarily aware of these exchanges, and will view the new data after the concert.

As the concerting band will be an hour late, the organizers send this information to the agents that manage the WiFi access points in the area. In turn, these agents disseminate the information to the devices connected to WiFi. The information is of great relevance to the participants, so it spreads fast among the devices of the people on the stadium. In case other users that are not participating to the event received the information, their AmI agents will discard it because their users are not participating in the event, so the information is not relevant.

Finally, the concert begins. Towards the end, a pyrotechnic event causes a fire on the stage. For security reasons, the public must be evacuated. Panic breaks out. The GSM network soon becomes unavailable and the WiFi hotspots are overloaded. Special emergency devices connect to Bluetooth phones that are located near the exists and send them directions towards the exit. From device to device, the urgent information quickly reaches all participants. AmI agents are capable of calculating the relevance of received information according to the number of links it went through, and choose which exit would be closer.

A few days after the concert, a group of participants that shared a lot of images and links, but not any personal details or contact information, want to find each other again. By using the concert site and the fact that they shared so much, their AmI agents are capable of communicating and the group can meet again. 


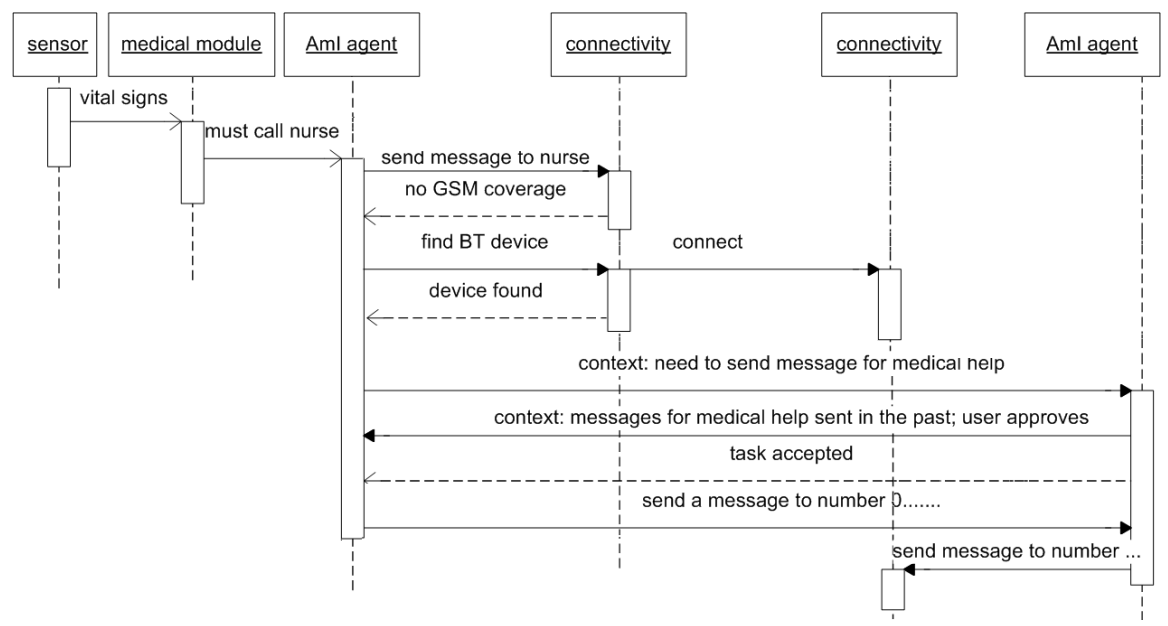

Fig. 1 Interactions between two AmI agents situated on two different devices (Scenario 1).

\section{Towards a Model for AmI}

AmI must be ubiquitous, pervasive, and it must be capable of managing a large number of mobile devices that incessantly share large quantities of information. More than that, its model must be reliable: in order to be invisible, people must not notice it is there, but also they must not notice when it is not. Considering AmI must be much more than the Internet is today, it must be a highly distributed system. Moreover, large quantities of the generated information will only be needed - and, indeed, make sense - inside a certain domain of space, time, activities and social relations (acquaintances). So AmI should work at a local level, using context-awareness to pick relevant information.

To further illustrate our vision for an Ambient intelligence architecture, we propose a model based on software agents, that uses local interaction and contextawareness.

Software agents [4] are very adequate for the purposes of AmI [6]: they offer proactivity, reactivity, autonomous behaviour, reasoning, learning and social abilities. In our model, one ore more software agents (called AmI agents) run on each device. Each agent is able to connect to AmI agents on other devices in the same area or (across the Internet) with AmI agents that are farther, but that share sufficient context.

Figure 1 presents the interaction between two AmI agents, according to Scenario 1 proposed in Section 3. The two agents are located on the two mobile devices involved. The physical connection is done locally, by Bluetooth, using the connectivity layer. No centralized services are used in the communication. An important role in the conversation is held by context: context information is exchanged between the agents, and each agent evaluates that information and detects context compatibility. 
In the other scenario as well, communication and the exchange of information is based on compatible context, and information from incompatible contexts (e.g. related to an event that the user does not participate and is not interested in) is discarded. Local interaction (local in terms of any type of context, not only spatial) makes the system distributed and keeps information stored only there where it is relevant. Like in Weiser's scenario, the agents only have the knowledge that may be useful. If the alarm clock is only told "yes" or "no", than it will be only these words that it will understand.

\section{Conclusion}

Ambient Intelligence is regarded as the third wave in computing and as the future of what is now the Internet. The features of AmI are described many times by means of scenarios which do not emphasize the requirements related to the scale of a real AmI system.

In this paper, we present several scenarios from previous work and we extract some central features and requirements of AmI, that we use for building two new scenarios and sketch a model for AmI that is based on system distribution and local interaction, using the detection of compatible context.

\section{References}

1. Banavar, G., Bernstein, A.: Software infrastructure and design challenges for ubiquitous computing applications. Communications of the ACM 45(12), 92-96 (2002)

2. Bohn, J., Coroama, V., Langheinrich, M., Mattern, F., Rohs, M.: Social, economic, and ethical implications of ambient intelligence and ubiquitous computing. Ambient intelligence pp. 5-29 (2005)

3. Ducatel, K., Bogdanowicz, M., Scapolo, F., Leijten, J., Burgelman, J.: Scenarios for ambient intelligence in 2010. Tech. rep., Office for Official Publications of the European Communities (2001)

4. Ferber, J.: Multi-agent systems: an introduction to distributed artificial intelligence. AddisonWesley (1999)

5. Kindberg, T., Barton, J., Morgan, J., Becker, G., Caswell, D., Debaty, P., Gopal, G., Frid, M., Krishnan, V., Morris, H., Schettino, J., Serra, B.: People, places, things: Web presence for the real world. Mobile Networks and Applications 7(5), 365-376 (2002)

6. Ramos, C., Augusto, J.C., Shapiro, D.: Ambient intelligence - the next step for artificial intelligence. IEEE Intelligent Systems 23(2), 15-18 (2008)

7. Satyanarayanan, M.: Pervasive computing: Vision and challenges. IEEE Personal communications 8(4), 10-17 (2001)

8. Vallée, M., Ramparany, F., Vercouter, L.: A multi-agent system for dynamic service composition in ambient intelligence environments. Advances in Pervasive Computing, Adjunct Proceedings of the Third International Conference on Pervasive Computing (Pervasive 2005) pp. $1-8(2005)$

9. Weiser, M.: The computer for the 21st century. Scientific American 272(3), 78-89 (1995) 